\title{
Glutathione may have implications in the design of 3-bromopyruvate treatment protocols for both fungal and algal infections as well as multiple myeloma
}

\author{
Katarzyna Niedźwiecka ${ }^{1}$, Mariusz Dyląg ${ }^{1, *}$, Daria Augustyniak², Grażyna Majkowska- \\ Skrobek², Magdalena Cal-Bąkowska ${ }^{1}$, Young H. Ko ${ }^{3}$, Peter L. Pedersen ${ }^{4}$, Andre \\ Goffeau $^{5}$, Stanisław Ułaszewski ${ }^{1, *}$ \\ ${ }^{1}$ Department of Genetics,Institute of Genetics and Microbiology, University of Wroclaw, Wroclaw, Poland \\ ${ }^{2}$ Department of Pathogen Biology and Immunology, Institute of Genetics and Microbiology, University of Wroclaw, Wroclaw, \\ Poland \\ ${ }^{3}$ KoDiscovery, LLC, UM BioPark, Baltimore, MD, USA \\ ${ }^{4}$ Departments of Biological Chemistry and Oncology and Sidney Kimmel Comprehensive Cancer Center (member at large), \\ Johns Hopkins University School of Medicine, Baltimore, MD, USA \\ ${ }^{5}$ Institut des Sciences de la Vie, Université Catholique de Louvain, Louvain-la-Neuve, Belgium \\ *These authors have contributed equally to this work \\ Correspondence to: Mariusz Dylag, email: mariusz.dylag@uwr.edu.pl \\ Stanisław Ułaszewski, email: stanislaw.ulaszewski@uwr.edu.pl \\ Keywords: 3-bromopyruvate (3BP), glutathione, buthionine sulfoximine, genes expression, fungi and MM cells \\ Received: January 05, $2016 \quad$ Accepted: August 13, $2016 \quad$ Published: August 25, 2016
}

\section{ABSTRACT}

In different fungal and algal species, the intracellular concentration of reduced glutathione (GSH) correlates closely with their susceptibility to killing by the small molecule alkylating agent 3-bromopyruvate (3BP). Additionally, in the case of Cryptococcus neoformans cells 3BP exhibits a synergistic effect with buthionine sulfoximine (BSO), a known GSH depletion agent. This effect was observed when 3BP and BSO were used together at concentrations respectively of 4-5 and almost 8 times lower than their Minimal Inhibitory Concentration (MIC). Finally, at different concentrations of 3BP (equal to the half-MIC, MIC and double-MIC in a case of fungi, 1 $\mathrm{mM}$ and $2.5 \mathrm{mM}$ for microalgae and 25, 50, $100 \mu \mathrm{M}$ for human multiple myeloma (MM) cells), a significant decrease in GSH concentration is observed inside microorganisms as well as tumor cells. In contrast to the GSH concentration decrease, the presence of 3BP at concentrations corresponding to sub-MIC values or half maximal inhibitory concentration ( $\mathrm{IC}_{50}$ ) clearly results in increasing the expression of genes encoding enzymes involved in the synthesis of GSH in Cryptococcus neoformans and MM cells. Moreover, as shown for the first time in the MM cell model, the drastic decrease in the ATP level and GSH concentration and the increase in the amount of ROS caused by ЗBP ultimately results in cell death.

\section{INTRODUCTION}

3-bromopyruvate (3BP) is a highly promising anticancer and antifungal drug $[1,2]$. Its activity is primarily based on the inhibition of pivotal enzymes of glycolysis, e.g., hexokinase-2, glyceraldehyde-3phosphate dehydrogenase (GAPDH) [3, 4], and lactate dehydrogenase $[4,5]$. Based on the fact that most types of cancer cells exhibit a Warburg effect, i.e., high glycolysis even in the presence of oxygen [6], such cells constitute an ideal target for 3BP, a potent inhibitor of both glycolysis and any remaining mitochondrial oxidative phosphorylation. This leads to rapid death of these cells $[4,5]$. Due to the structural similarity to key cellular metabolites, i.e., lactate and pyruvate, 3BP may enter tumor or fungal cells using lactate/pyruvate transporters [7-9]. In contrast, as shown in numerous studies, 3BP's cytotoxicity to healthy mammalian cells is minimal or non-existent [10]. In addition, 3BP inhibits tumor angiogenesis by inhibiting the formation of vascular 
branching points, reducing the length of vascular tubes, and inhibiting vascular tubulogenesis [11].

Among the changes induced by $3 \mathrm{BP}$ at the cellular level, one of the most significant shown in this study is a decrease in the concentration of reduced glutathione (GSH). GSH is a tripeptide thiol consisting of glutamate, cysteine and glycine and is commonly found in eukaryotic and prokaryotic cells. GSH contains a very reactive thiol group (-SH) which makes it a major cellular antioxidant [12]. In addition, it seems that GSH is involved in the repair of DNA as the accumulation of DNA damage was observed in organs of mice that exhibit a defect in GSH metabolism that causes a decrease in the concentration of GSH [13]. High levels of GSH in tumor cells provide significant protection against reactive oxygen species (ROS) thus effectively keeping such cells from undergoing apoptosis [14] and therefore remaining immortal.

In this paper we have examined the phenomenon of apoptosis and necrosis induction by $3 \mathrm{BP}$ in the context of GSH and ROS. We have noted that various types of eukaryotic cells are characterized by different natural levels of intracellular GSH. A similar situation was previously described for different species of fungi [15]. Also, our previous studies showed 3BP to exhibit species differentiated antifungal properties. In addition, a significant correlation was found between MIC values for 3BP and the normal cellular concentration of GSH [15]. Therefore, the efficiency of 3BP is clearly dependent on the intracellular level of GSH, and it is not surprising that this agent exhibits a synergistic effect with the known GSH depletors including such compounds as buthionine sulphoximine (BSO), methionine sulfoximine (MSO) and paracetamol (acetaminophen). It is well known for mammalian cells that all of these compounds act as GSH depletors [16-18]. Both BSO and MSO are irreversible inhibitors of $\gamma$-glutamylcysteine synthetase and glutamine synthetase respectively, thus reducing the intracellular GSH level $[16,17]$, whereas paracetamol is metabolized to cytotoxic N-acetyl-4-benzoquinoneimine (NAPQI) that binds directly to the GSH $[18,19]$. In this paper we have also shown that $3 \mathrm{BP}$ and BSO exhibit a very strong synergistic effect in Cryptococcus neoformans cells. Moreover, the stimulating effect of $3 \mathrm{BP}$ on the higher expression of genes involved in GSH metabolism has not been previously tested. Although, the important role of GSH is not questionable, it should be noted as previously described that differences in 3BP transport into cells of species differentiated fungi are related directly to observed differences in their susceptibility to this compound [15].

\section{RESULTS}

The results of susceptibility tests performed on different fungal cells and micro-algal strains used as models are presented in Table 1. We have observed very different susceptibilities toward 3BP with Minimal Inhibitory Concentration (MIC) values ranging from
0.15 to $8.4 \mathrm{mM}$. As reported previously, the highest susceptibility toward this compound was shown for Cryptococcus neoformans and the lowest for Exophiala dermatitidis [15]. Moreover, as predicted synthetic GSH directly added to the SD medium abolished 3BP's inhibitory capacity. In the presence of $5 \mathrm{mM} \mathrm{GSH}$ (reduced) in SD medium containing 3BP at a concentration equal to the MIC value $(0.2 \mathrm{mM})$ for the most resistant strain of Cryptococcus neoformans, the growth of all tested Cryptococcus neoformans strains was restored to that observed for the growth control (Figure 1a).

In addition to the just noted results, it was shown also that the combination of low concentrations (significantly below the MIC) of 3BP and BSO completely inhibited growth of the tested Cryptococcus neoformans strains (Figure 1b). This effect was apparent when 3BP and BSO were used in combination at concentrations respectively of 4-5 and almost 8 times lower than their MICs (Table 2). Of the five Cryptococcus neoformans strains used in this study, the MIC of 3BP was lowered to values equal to $0.03-0.04 \mathrm{mM}$ when the SD medium simultaneously contained BSO at a concentration between 8-10 mM. These results clearly indicate a synergistic interaction between $3 \mathrm{BP}$ and $\mathrm{BSO}$.

Moreover, it should be emphasized that we observed a strong correlation between the natural intracellular concentration of GSH and the susceptibility of cells of the analyzed strains toward 3BP. We have demonstrated a high diversity in terms of intracellular levels of the reduced form of glutathione inside cells of species differentiated strains of fungi and microalgae. Both for tested strains of fungi (Figure 2a) as well as algal strains belonging to the Prototheca genus (Figure 2b), we could observe that strains most susceptible to 3BP also have the lowest level of GSH inside their cells (Table 1). In order to examine the effect of 3BP on the intracellular concentration level of GSH, we measured the concentration of this tripeptide in cells of the selected strains which were incubated for a defined time in the presence of appropriate concentrations of this compound. In the case of cells from fungi and algae, we observed after 20 minutes of incubation in the presence of $3 \mathrm{BP}$ a significant decrease in GSH concentration. After $1 \mathrm{~h}$ the concentration remained low or further decreased. During the entire experiment, the viability of cells fluctuated between 80 to $100 \%$ depending on the strain and the concentration of 3BP (Figure $3 \mathrm{a}$ and $3 b)$. The same observation was made in the case of MM cells. For cell cultures incubated in the presence of various concentrations of 3BP a decrease in GSH concentration was also observed, while their viability was not affected relative to control cells free of this compound (Figure 4). Here, it should be emphasized that during this experiment we observed changes in the morphology of MM cells in the case of samples incubated for $2 \mathrm{hrs}$ in the presence of $3 \mathrm{BP}$ at concentrations equal to $50 \mu \mathrm{M}$ and $100 \mu \mathrm{M}$ (Figure 5a-5c). No morphological changes were observed in the case of fungal and microalgae cells. 
Table 1: Susceptibility of fungal and micro-algal strains used in this study toward 3BP evaluated by the spot-test method and the indicated concentrations of endogenous intracellular GSH

\begin{tabular}{lcc}
\hline Tested strains & $\begin{array}{c}\text { MIC of 3BP } \\
{[\mathbf{m M}]}\end{array}$ & $\begin{array}{c}\text { GSH } \\
{\left[\boldsymbol{\mu m o l} / \mathbf{1 0} \mathbf{0}^{\mathbf{c}} \mathbf{c e l l s}\right]}\end{array}$ \\
\hline Cryptococcus neoformans H99 & 0.15 & $0.4 \pm 0.052$ \\
Cryptococcus gattii R265 & 0.6 & $0.48 \pm 0.035$ \\
Cryptococcus uniguttulatus MD1 & 2.4 & $0.85 \pm 0.109$ \\
Exophiala dermatitidis MD1 & 8.4 & $1.04 \pm 0.052$ \\
Prototheca zopfii & 2.5 & $2.05 \pm 0.40$ \\
Prototheca wickerhamii & 3.0 & $2.89 \pm 0.13$ \\
Prototheca blaschkeae & 3.5 & $4.86 \pm 0.22$ \\
Prototheca zopfii var. hydrocarbonea & 3.5 & $5.73 \pm 0.61$ \\
\hline
\end{tabular}

a

\begin{tabular}{|c|c|c|c|c|c|}
\hline $\begin{array}{l}\text { C. neoformans } \\
\text { strains }\end{array}$ & Growth control & \multirow[t]{2}{*}{$0.2 \mathrm{mM} \mathrm{3BP}$} & \multicolumn{3}{|c|}{$0.2 \mathrm{mM} 3 \mathrm{BP}+5 \mathrm{mM}$ GSH } \\
\hline H99 & (2) & & $\mathrm{O}$ & w & \\
\hline CAP59 & 6 球。 & & 0 & s: & ; \\
\hline 201 & 0 ह & & 0 & है & : \\
\hline $\mathrm{AM} / 08$ & (-) & & O & is & 8 \\
\hline No.8 & 00 & & 0 & 항 & $w$ \\
\hline
\end{tabular}

b

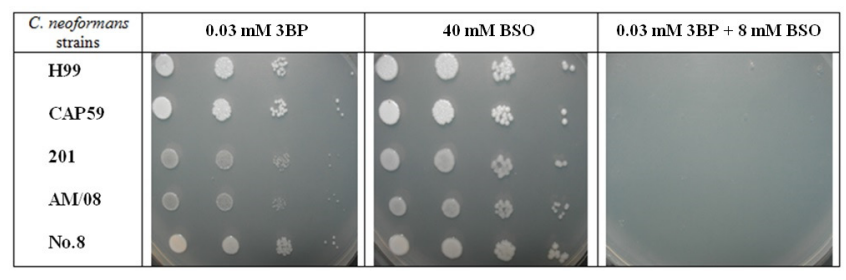

Figure 1: a, b. Growth after $72 \mathrm{hrs}$ of incubation at $28^{\circ} \mathrm{C}$ of clinical and laboratory strains of Cryptococcus neoformans on minimal SD medium in the presence of 3BP, GSH and BSO used solely or in combination.

Table 2: The MIC and FICI values determined for 3BP and BSO (used solely or in combination) in the case of tested Cryptococcus neoformans cells*

\begin{tabular}{lccc}
\hline Compounds & MIC $^{\#}$ alone & MIC combined & FICI ${ }^{\# \#}$ \\
\hline 3BP & $0.15-0.2$ & $0.03-0.04$ & $0.33-0.38[\mathrm{~S}]$ \\
BSO & $60-80$ & $8-10$ & \\
\hline
\end{tabular}

\# MIC - Minimal Inhibitory Concentration given at mM of active compound;

\# FICI - Fractional Inhibitory Concentration Indices;

*Tests performed on modified minimal synthetic medium (SD) with glucose replaced by sucrose (2\%), pH 5.5. Five clinical Cryptococcus neoformans strains were included in this study.

a

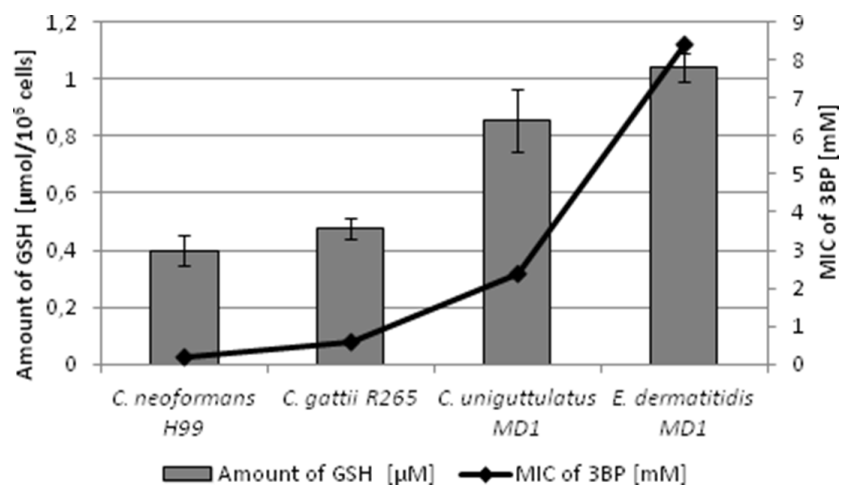

b

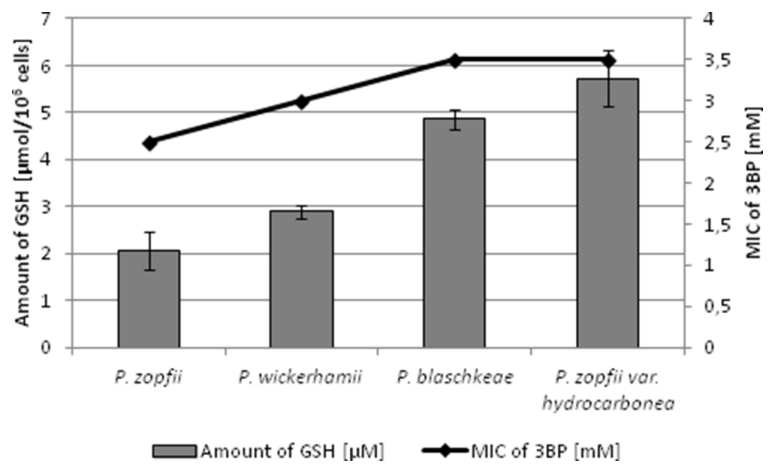

Figure 2: a, b. Comparison of the MIC values of 3BP and the concentration of intracellular GSH in fungal (a) and algal (b) cells. 


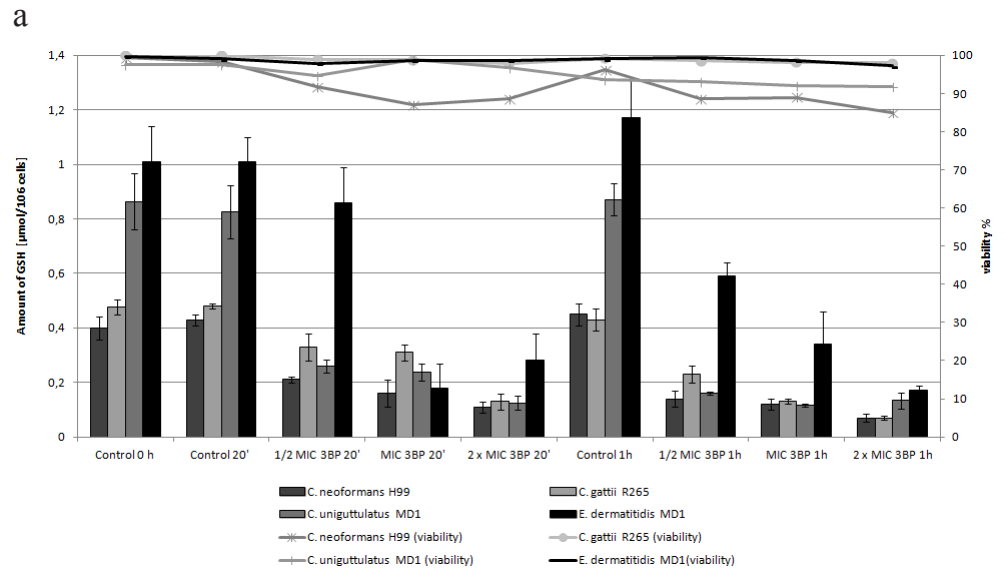

b

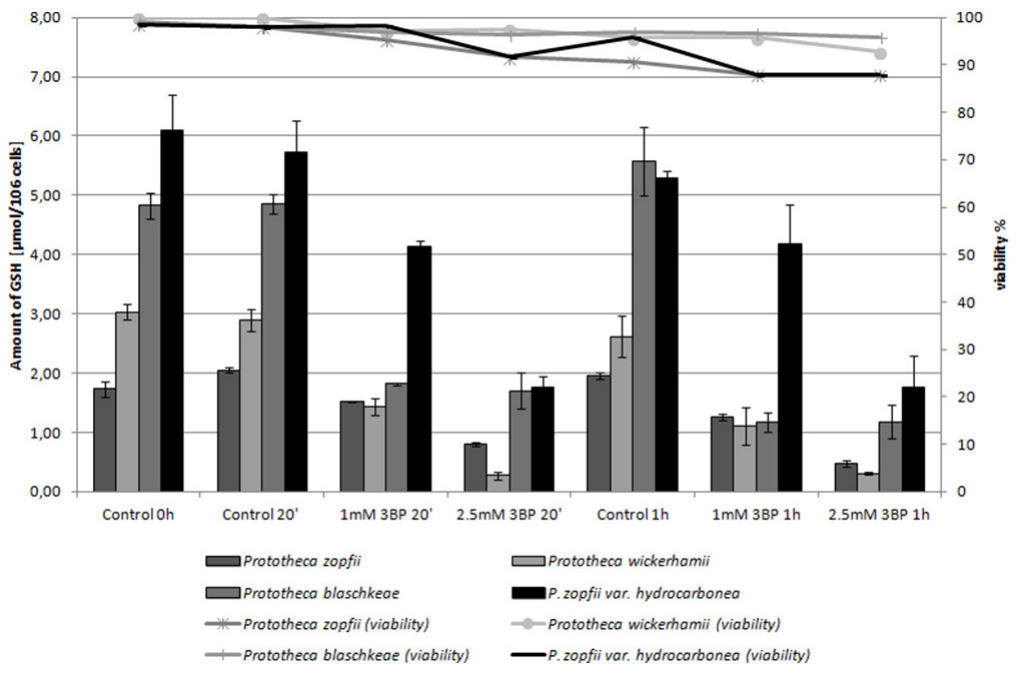

Figure 3: a. Influence of 3BP on the viability and GSH concentration inside cells of selected fungi. b. Influence of 3BP on the viability and GSH concentration inside Prototheca spp. cells.

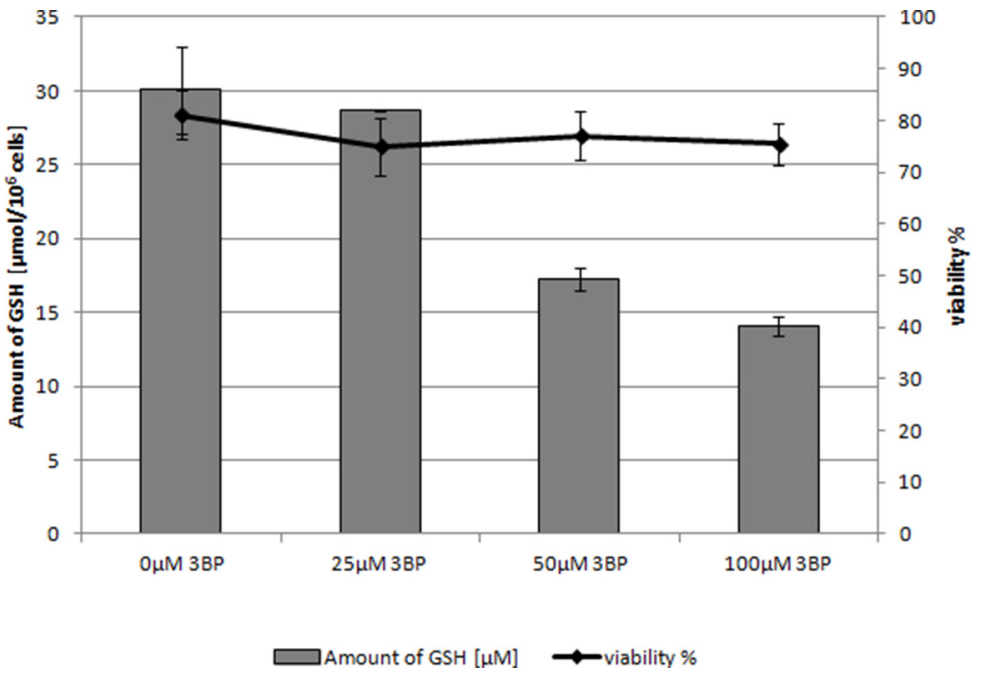

Figure 4: The concentration of intracellular GSH in MM cells (RPMI 8226) after 2 hrs incubation in the presence of $3 B P$. 
a

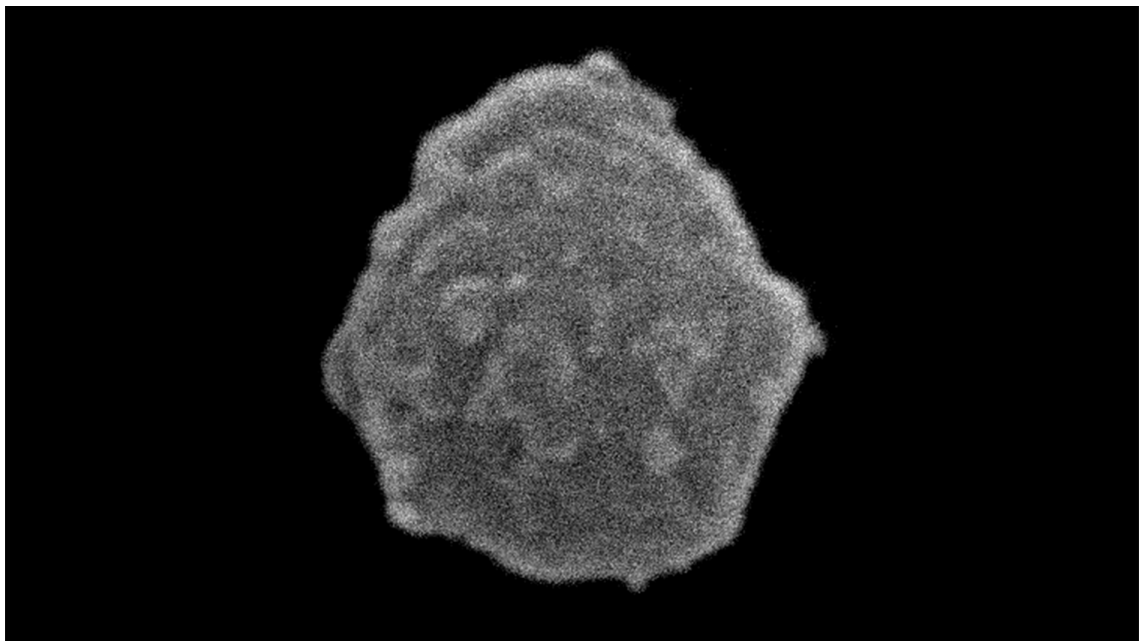

b
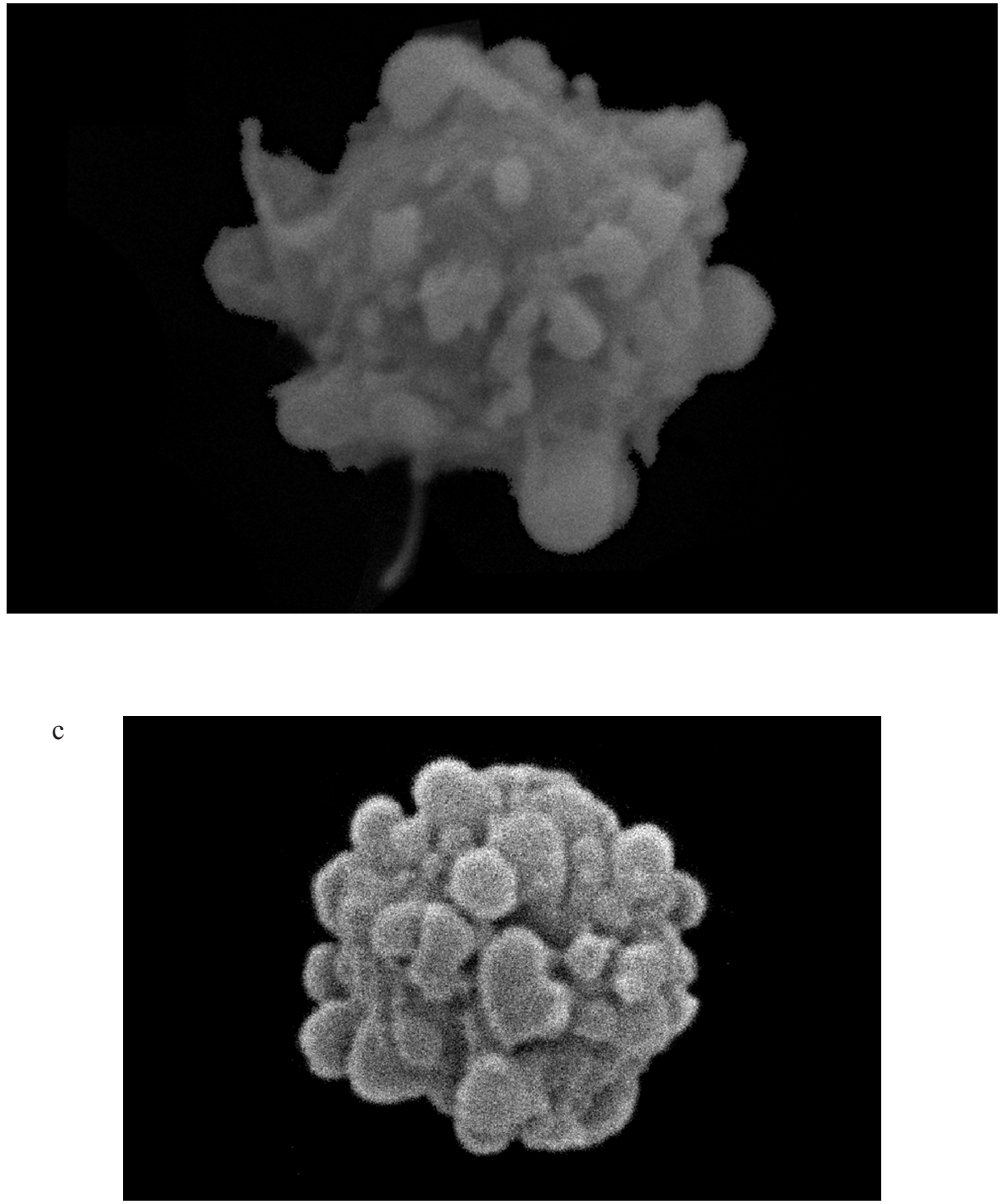

Figure 5: a-c. Changes in MM cell morphology under the influence of 3BP (a- $0 \mu \mathrm{M}, \mathrm{b}-50 \mu \mathrm{M}$ and c- $100 \mu \mathrm{M})$ after 2 hrs incubation (SEM, magnification - 5700×). 
Observed morphological changes appear to result from apoptosis [20]. In order to determine the cause of morphological changes of MM cells under the influence of $3 \mathrm{BP}$, we have conducted the apoptosis assays. After $2 \mathrm{hrs}$ of incubation in a presence of $25 \mu \mathrm{M} 3 \mathrm{BP}$ the percentage of viable, early apoptotic, late apoptotic and necrotic cells was similar to the control sample without 3BP. However, after addition of 50 and $100 \mu \mathrm{M}$ of $3 \mathrm{BP}$ we observed a significant decrease in the number of viable cells, i.e., from $\sim 70 \%$ to $\sim 50 \%$ with a simultaneous increase in the percentage of necrotic cells and a slight increase in the number of late apoptotic cells (Figure 6).

3BP also influences the generation of reactive oxygen species (ROS) in MM cells. We have clearly observed an increase in the reactive oxygen concentration even at the lowest concentration used for 3BP (25 $\mu \mathrm{M})$ after $4 \mathrm{hrs}$ incubation. In this case the amount of ROS increased by $\sim 35 \%$ compared to the control without 3BP. After $4 \mathrm{hrs}$ incubation in the presence of 50 and $100 \mu \mathrm{M} 3 \mathrm{BP}$ the increase was $\sim 55 \%$ and $\sim 59 \%$ respectively. In contrast, after 2 hrs incubation, changes in the concentration of ROS were much less. Thus, concentrations of 3BP equal to 25,50 and $100 \mu \mathrm{M}$ caused approximately 5\%, 9\% and $13 \%$ increase in ROS level, respectively (Figure 7).

The important role of GSH in the susceptibility of $\mathrm{MM}$ cells to $3 \mathrm{BP}$ is also clearly visible when the expression level of the genes involved in the metabolism of GSH

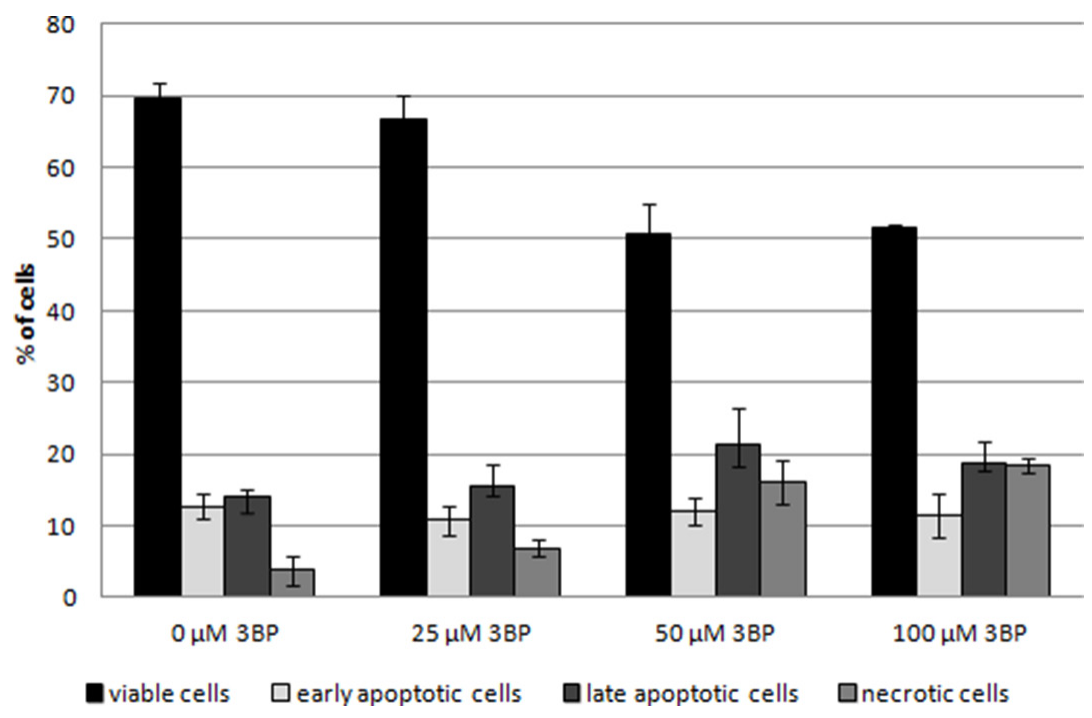

Figure 6: Induction of the apoptosis in MM cells after 2 hrs incubation in the presence of $0 \mu M, 25 \mu M, 50 \mu M$ and $100 \mu \mathrm{M} 3 \mathrm{BP}$.

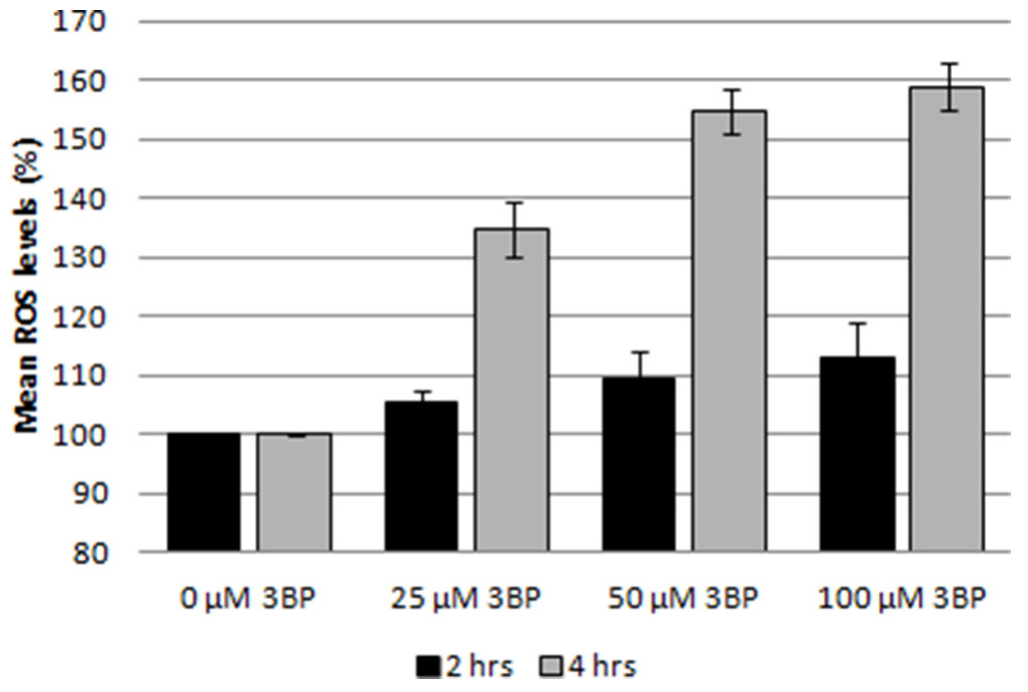

Figure 7: Influence of 3BP (at concentrations of $25 \mu \mathrm{M}, 50 \mu \mathrm{M}$ and $100 \mu \mathrm{M}$ ) on the generation of ROS in MM cells after 2 and 4 hrs incubation. 
under the influence of 3BP are analyzed. In comparing the levels of expression of genes encoding $\gamma$-glutamylcysteine synthetase (GCLC and CNAG_06300) and glutathione synthetase (GSS, CNAG_04647) incubated in the presence of various concentrations of 3BP $(25 \mu \mathrm{M}$ for MM cells and $75 \mu \mathrm{M}$ or $150 \mu \mathrm{M}$ for Cryptococcus neoformans), we observed a significant increase in both MM and Cryptococcus neoformans cells. In the case of MM cells we also noted that the expression of the GCLC gene was significantly higher after $4 \mathrm{hrs}$ incubation in the presence of 3BP than after $2 \mathrm{hrs}$. Moreover, we have reported that the genes encoding glutathione S-transferase (GSTP1, CNAG_01893) in MM and Cryptococcus neoformans cells are also overexpressed under the presence of 3BP. In addition, we observed a slight increase in the expression of the gene that encodes glutathione peroxidase in MM cells. However, we did not note this in the case of Cryptococcus neoformans. Rather we reported a strong overexpression of the CNAG_02399 gene encoding glutathione reductase in Cryptococcus neoformans. However, the expression level of the GRS gene encoding the same enzyme in MM cells was comparable to the control incubated without 3BP (Figure 8a, 8b). Therefore, we can conclude that while on the one hand our studies show that 3BP causes a decrease in the intracellular GSH concentration, on the other hand 3BP causes a significant increase in the expression level of genes encoding the enzymes contributing to increasing the intracellular concentration of GSH.

\section{DISCUSSION}

The susceptibility tests performed for 3BP and BSO alone and in combination on the Cryptococcus neoformans cell model allowed us to show significant hyper-synergism between these compounds. The Fractional Inhibitory Concentration Indices (FICI values) were between 0.33 and 0.38 , i.e., below the upper limit value (0.5). We know that BSO causes irreversible

a

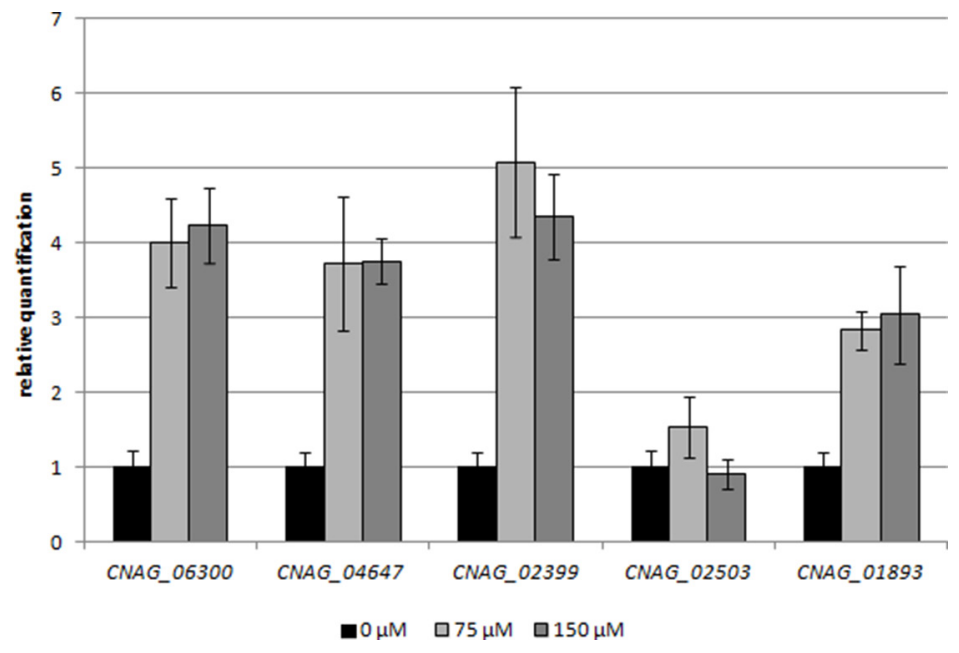

b

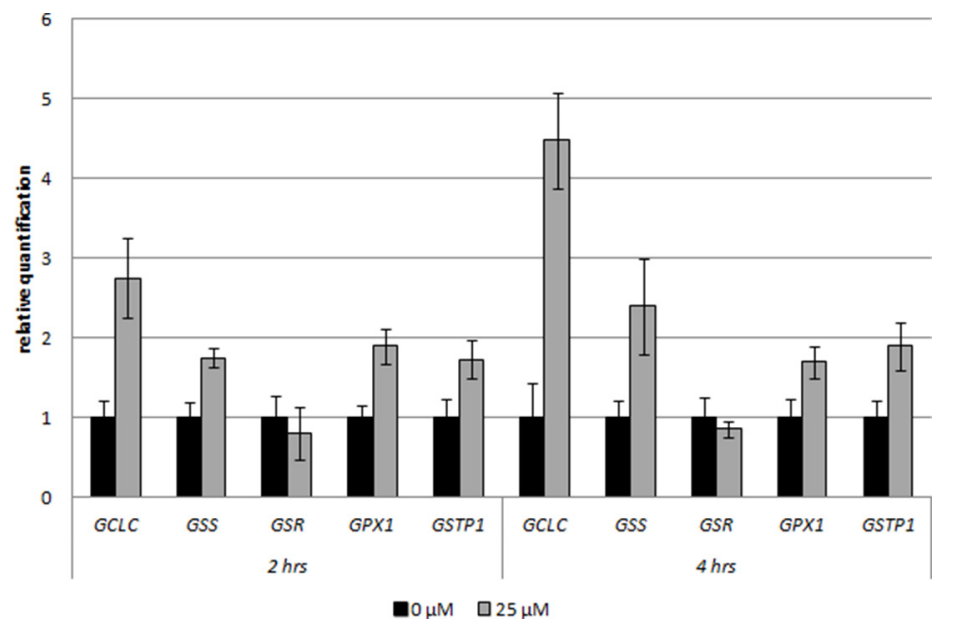

Figure 8: a, b. Impact of 3BP on the level of expression of selected genes involved in the metabolism of glutathione in Cryptococcus neoformans H99 cells after 4 hrs incubation (a), MM cells after 2 and 4 hrs incubation (b) (GCLC and CNAG_06300 encode $\gamma$-glutamylcysteine synthetase, GSS and CNAG_04647-glutathione synthetase, GSR and CNAG_02399-glutathione reductase, GPX1 and CNAG_02503-glutathione peroxidase, GSTP1 and CNAG_01893-glutathione S-transferase). 
inhibition of $\gamma$-glutamylcysteine synthetase and for this reason effectively blocks GSH synthesis causing a drastic decrease in its intracellular concentration [16]. In our previous studies we observed similar results with MM cells where pretreatment with $100 \mu \mathrm{M}$ BSO decreased the half maximal inhibitory concentration $\left(\mathrm{IC}_{50}\right)$ for $3 \mathrm{BP}$ from approximately $25 \mu \mathrm{M}$ to $13 \mu \mathrm{M}$ [21]. Additional confirmation for an important role for GSH in the generation of a phenotype resulting in natural resistance to 3BP in Cryptococcus neoformans cells are results of tests performed with the same SD medium supplemented with GSH at a concentration of $5 \mathrm{mM}$. Thus, we observed about an 8-fold decrease in susceptibility to 3BP. These results allow us to conclude that $3 \mathrm{BP}$ in direct combination with GSH manifests an antagonistic effect.

The study performed on MM cells to determine the impact of 3BP on intracellular GSH concentration resulted in an interesting phenomenon. Thus, the specific morphology of MM cells treated with high concentrations of $3 \mathrm{BP}(50 \mu \mathrm{M}$ and $100 \mu \mathrm{M})$ resulted in an advanced stage of apoptosis. This was the case for approximately $20 \%$ of the total number of cells and confirmed by an apoptosis assay. Thus, after 2 hrs exposure to $3 \mathrm{BP}$ we observed the well described morphology of apoptotic cells [20]. They appeared highly dehydrated with drastic changes in shape. In addition, we observed cells that were mainly rounding and shrinking with characteristic membrane bubbles as described many times earlier [20, 22, 23]. Also, it was well demonstrated [22], that the apoptotic cells exhibit the typical disintegration of the nuclear membrane and subsequent nuclear fragmentation. This phenomenon is explained by the so-called CAD/ICAD system. CAD is a specific DNase that in most proliferating cells is expressed as an inactive enzyme complexed with ICAD (inhibitor of CAD). Under the influence of 3BP or other agents that induce apoptosis caspase 3 cleaves ICAD and CAD which causes DNA degradation. Chromatin fragments and cellular organelles become surrounded by portions of the plasma membrane resulting in so-called "apoptotic bodies" that may be phagocytosed later by macrophages [20, 23]. Despite the fact that after incubation for $2 \mathrm{hrs}$ with $3 \mathrm{BP}$ (50 and $100 \mu \mathrm{M}$ ), the percentage of apoptotic cells only slightly increased is in an accordance with the image morphology. Upon microscopic observation we noted that about $20 \%$ of the MM cells exhibited characteristic morphological changes. This observation, taken together with the results from flow cytometry, suggest that the initial stage of apoptosis is in progress. This supposition was confirmed by an apoptosis assay that we made upon incubation with $3 \mathrm{BP}$ for $18 \mathrm{hrs}$ (data not shown). Thus, using $100 \mu \mathrm{M} 3 \mathrm{BP}$ we observed the following percentage of viable, early apoptotic, late apoptotic and necrotic cells respectively: $1.5 \%, 13.5 \%, 83 \%$ and $2 \%$, This outcome supports the view that following treatment with 3BP the number of dead cells due to apoptosis increases with time. Similar observations of morphological changes resulting from treatment with 3BP were observed in an earlier study with hepatocellular carcinoma cells [24].

The most important action of 3BP, i.e., that on cancer cells has been described previously. Thus, 3BP has been shown to be as a strong inhibitor of glycolytic and mitochondrial function [25] and thus results in depletion of intracellular ATP $[15,21,26]$. In addition, we have shown that $3 \mathrm{BP}$ targets other cellular areas in MM cells, one of which results in induction of oxidative stress. The resultant increase in ROS (reactive oxygen species) following treatment with 3BP has been observed also in hepatoma cells SNU449 and Hep3B [27], glioma cells [11], HL60 cells [28] and in breast cancer cells (MDA-MB-231, MDA-MB-435) [29]. In all these cases, this phenomenon is likely caused by inhibition of the mitochondrial respiratory chain which leads to the accumulation of intracellular ROS.

In contrast to that noted above, the sensitivity of tested fungi and microalgae species toward 3BP was found to be quite different. Among other factors, their susceptibility depends on the concentration of intracellular GSH as shown earlier [15] as well as in the present study. Therefore, it should be clear as to why a higher concentration of the reduced form of GSH inside cells of fungi results in their higher resistance to $3 \mathrm{BP}$. This resistance is likely due to the function of GSH as the main cellular antioxidant [12, 30]. Furthermore, in the presence of 3BP a decrease in GSH levels in cells of all tested fungal and microalgae strains was observed. A significant decrease of reduced GSH concentration with strong inhibition of antioxidant enzymes such as superoxide dismutase and glutathione S-transferase was shown also in a human erythrocyte model [31]. A decrease of intra-cellular GSH levels mainly occurs due to the action of the enzyme glutathione S-transferase. This enzyme is responsible for generating 3BP-GSH conjugates consistent with it often being referred to as a fundamental detoxification enzyme [32]. This reaction occurs in the cytoplasm and as a result is non-toxic for cell conjugates which are transferred to the vacuole [33]. Our experiments showed that the above reaction takes place most likely with no loss of cell viability. This is because the survival of all tested strains was very similar to that of the control.

On the one hand we found that 3BP can bind directly to GSH and on the other that $3 \mathrm{BP}$ alters the expression level of genes encoding enzymes involved in the metabolism of this tripeptide thiol. The most significant change was the over expression of genes encoding $\gamma$-glutamylcysteine synthetase and glutathione synthetase both in MM and Cryptococcus neoformans cells. This phenomenon occurs most likely as a response caused by the action of highly reactive alkylating xenobiotics like 3BP. Such cells need more GSH in order to inactivate the harmful compound and therefore increase the expression of genes encoding the enzymes involved in its synthesis. Consequently, in both organisms we could also observe an increase in the expression of the gene encoding 
glutathione S-transferase an enzyme that catalyzes the coupling reaction of GSH with nucleophilic and electrophilic compounds $[34,35]$. The increased expression of this gene is most likely a response to a higher demand for formation of GSH-xenobiotic complexes to inactivate $3 \mathrm{BP}$ and protect the cell. Such a response is rationale and in fact has been noted in the literature. Thus, key enzymes such as glutathione S-transferase, $\gamma$-glutamylcysteine synthetase and glutathione synthetase are highly expressed in cells subjected to stress conditions [36].

Although the intracellular concentration of GSH is very important for 3BP's action and may have implications for clinical treatment of fungal infections and cancer, the entry of 3BP via mono-carboxylate transporters seems to be more essential for treating cancers than fungal related diseases. This was demonstrated in earlier studies by using various fungi $[8,15]$ and erythrocytes [37]. In the latter study it was shown that 3BP uptake depends significantly on $\mathrm{pH}$ in the range of 6.0-8.0 [37]. In addition, the affinity for 3BP transport into breast cancer cell lines is higher when the extracellular milieu is acidic suggesting that the uptake of 3BP may be dependent on the proton-motive force [9]. In summary, we can state that it is easier to overcome an internal barrier in the forms of intracellular GSH than overcome the entry of 3BP via MCTs. The last mentioned phenomenon was reported in our earlier studies with Saccharomyces cerevisiae cells [8]. Moreover, it was shown that the $3 \mathrm{BP}$ molecule is not a substrate for the pleiotropic drug resistance network (PDR) [8], thus excluding this route to cell detoxification. Regarding the clinical implications of these findings one can say that a special diet and/or BSO may be necessary to eliminate a high glutathione concentration in a patient's body in order to facilitate effective treatment with 3BP.

\section{MATERIALS AND METHODS}

\section{Reagents}

All reagents if not otherwise mentioned were purchased from Sigma-Aldrich (Poland) and were of analytical grade.

\section{Fungal and algal strains, MM cell cultures and growth conditions}

All fungal and algal strains used in this study are listed in Table 3. These strains were isolated from either humans or animals and from the environment as well.

All tested strains were grown at $28^{\circ} \mathrm{C}$ in complete YPD medium $(2 \% \mathrm{w} / \mathrm{v}$ peptone, $1 \% \mathrm{w} / \mathrm{v}$ yeast extract, $\mathrm{pH}=5.5)$ and in synthetic minimal SD medium $(0.67 \%$ $\mathrm{w} / \mathrm{v}$ of yeast nitrogen base without amino acids, $\mathrm{pH}=5.5$ ). Both types of media contained $2 \% \mathrm{w} / \mathrm{v}$ glucose (in case of algal strains) or sucrose (in case of fungi) as a sole carbon source. All the used media were solidified by agar $(2 \%$ w/v, Difco). The RPMI 8226 (ATCC ${ }^{\circledR}$ CCL155 $^{\mathrm{TM}}$ ) cell line (MM.1 human multiple myeloma) was obtained from the Cell Culture Collection of the Institute of Immunology and Experimental Therapy, Polish Academy of Science, Wroclaw, Poland. The cell cultures were propagated in complete medium (RPMI1640 medium supplemented with $2 \mathrm{mmol} / \mathrm{l}$ glutamax, $1 \% \mathrm{w} / \mathrm{v}$ antibiotic-anti-mycotic solution, and $10 \% \mathrm{w} / \mathrm{v}$ heat-inactivated fetal bovine serum) at $37^{\circ} \mathrm{C}$ in a humidified atmosphere with $5 \% \mathrm{w} / \mathrm{v} \mathrm{CO}_{2}$.

\section{Susceptibility testing}

The minimal inhibitory concentration (MIC) values of 3BP and BSO and for combination of these compounds were determined according to a standard spot test method [38]. Fungal and micro-algal cells were grown to an exponential phase and then diluted to an $\mathrm{OD}_{600 \mathrm{~nm}} \approx 0.125$ and spotted $(5 \mu \mathrm{l})$ in ten-fold serial dilutions $\left(10^{\circ}, 10^{-1}, 10^{-}\right.$ $\left.{ }^{2}, 10^{-3}\right)$ onto agar plates containing various concentrations of the tested compound. Plates were incubated at $28^{\circ} \mathrm{C}$ and photographs were made after $72 \mathrm{hrs}$ (after which we could observe good growth on plates designed for growth control). In addition, the impact of reduced glutathione (synthetic GSH directly added to the SD medium) on its susceptibility to 3BP was monitored (Figure 1b). The susceptibility tests were performed using minimal SD medium with $2 \% \mathrm{w} / \mathrm{v}$ sucrose as the sole carbon source. All tested compounds: GSH (synthetic glutathione), BSO (buthionine sulfoximine) and 3BP (3-bromopyruvate) were dissolved in sterile deionized water (milli Q).

The type of interactions between $3 \mathrm{BP}$ and $\mathrm{BSO}$ were defined based on calculations of the Fractional Inhibitory Concentration Indices (FICI) [39], where (in this case) $\mathrm{FICI}=(\mathrm{MIC}$ of $3 \mathrm{BP}$ in combination with $\mathrm{BSO} / \mathrm{MIC}$ of $3 \mathrm{BP}$, alone $)+(\mathrm{MIC}$ of $\mathrm{BSO}$ in combination with 3BP/MIC of BSO alone). Interactions between compounds were defined as $[\mathrm{S}]$ hyper-synergism $(\mathrm{FICI} \leq 0.5),[\mathrm{A}]$ additive synergism $(0.5<\mathrm{FICI} \leq 1),[\mathrm{N}]$ neutral action $(1<\mathrm{FICI} \leq$ $2)$ or $[\mathrm{An}]$ antagonistic action $(2<\mathrm{FICI})$.

\section{Determination of GSH concentration}

Aliquots of $25 \mathrm{ml}$ each were obtained from overnight fungal and algal cultures which had reached an exponential phase of growth $\left(\mathrm{OD}_{600 \mathrm{~mm}}=1.5-1.8\right)$. Then, into Erlenmeyer flasks $3 \mathrm{BP}$ at the appropriate concentration was added to those intended as positive controls while in other flasks 3BP was omitted (negative controls). All samples were incubated for a suitable time at $28^{\circ} \mathrm{C}$ with horizontal shaking $(200 \mathrm{rpm} / \mathrm{min})$. Extraction of metabolites was carried out based on the method described by Gonzales et al. [40]. For this purpose the whole fungal or algal cell cultures $(25 \mathrm{ml})$ were centrifuged. To the resulting pellet was added $5 \mathrm{ml}$ of buffered boiling ethanol (75\% ethanol, $70 \mathrm{mM}$ HEPES, $\mathrm{pH}$ 7.5). Then, samples were incubated for $3 \mathrm{~min}$ at $80^{\circ} \mathrm{C}$ and for the next 3 min cooled 
Table 3: Fungal and micro-algal strains used in this study and their source

\begin{tabular}{lcc}
\hline Taxonomic position & Strain & Source \\
\hline Fungi & Cryptococcus neoformans H99 & Heitman $^{1}$ (clinical strain) \\
Cryptococcus neoformans CAP59 & Deck $^{2}$ (laboratory strain) \\
Cryptococcus neoformans 201 & Nawrot $^{3}$ (clinical strain) \\
& Cryptococcus neoformans AM/08 & Dyląg $^{4}$ (clinical strain) \\
& Cryptococcus neoformans No.8 & Dyląg $^{4}$ (clinical strain) \\
& Cryptococcus gattii R265 & May $^{5}$ (clinical strain) \\
& Cryptococcus uniguttulatus MD1 & Dyląg $^{4}$ (environmental strain) \\
Exophiala dermatitidis MD1 & Dyląg $^{4}$ (clinical strain) \\
Plgae & Prototheca wickerhamii & Jagielski $^{6}$ (clinical strain) \\
& Prototheca blaschkeae & Jagielski $^{6}$ (clinical strain) \\
& Prototheca zopfii var. hydrocarbonea & Jagielski $^{6}$ (clinical strain) \\
\end{tabular}

${ }^{1}$ Joseph Heitman - Department of Molecular Genetics and Microbiology, Duke University School of Medicine, Durham, USA

${ }^{2}$ Hans de Cock - Department of Biology, Microbiology, Institute of Biomembranes, Utrecht University, Utrecht, The Netherlands

${ }^{3}$ Urszula Nawrot - Department of Microbiology, Wroclaw Medical University, Chalubinskiego Street 4, Wroclaw, Poland

${ }^{4}$ Mariusz Dyląg - Department of Genetics, Institute of Genetics and Microbiology, University of Wroclaw,

Przybyszewskiego Street 63/77, Wroclaw, Poland

${ }^{5}$ Robin May - School of Biosciences and Institute of Microbiology \& Infection, University of Birmingham, Edgbaston, Birmingham, United Kingdom

${ }^{6}$ Tomasz Jagielski - Department of Applied Microbiology, Institute of Microbiology, University of Warsaw, Miecznikowa 1

Street, Warsaw, Poland

on ice. Subsequently, all the samples were subjected to evaporation in a vacuum dryer for $3 \mathrm{hrs}$ at $45^{\circ} \mathrm{C}$. The intracellular concentration of GSH was determined by using Ellman's reagent [41] as previously described [13]. In the case of MM cells, each sample contained $\sim 4.5 \mathrm{x}$ $10^{6}$ cells. The samples were incubated for $2 \mathrm{hrs}$ at $37^{\circ} \mathrm{C}$ in the presence of an appropriate concentration of $3 \mathrm{BP}$. The next steps (metabolite extraction, determination of GSH concentration) were identical for both fungi and microalgae. Cell viability was determined by staining with methylene blue (fungi and Prototheca) or trypan blue (MM cells).

\section{Induction of apoptosis by $3 \mathrm{BP}$}

The induction of apoptosis following the action of 3BP was measured using the Dead Cell Apoptosis Kit with Annexin V FITC (AV) and Propidium iodide (PI) (Life Technologies). MM cells at a concentration of 2.5 $\times 10^{5}$ cells per milliliter were treated with the appropriate concentration of $3 \mathrm{BP}(0 \mu \mathrm{M}, 25 \mu \mathrm{M}, 50 \mu \mathrm{M}$ and $100 \mu \mathrm{M})$ and camptothecin $(5 \mu \mathrm{M})$ as a positive control. Cells were incubated at $37^{\circ} \mathrm{C}$ under $5 \% \mathrm{CO}_{2}$ for $2 \mathrm{hrs}$. Using
BD FACSCalibur ${ }^{\mathrm{TM}}$, the fluorescence was detected. Cells were classified as follows: viable cells (AV-/PI-), early apoptotic cells (AV+/PI-), late apoptotic cells (AV+/PI+) and necrotic cells (AV-/PI+).

\section{Determination of the ROS level}

Differences in the generation of free radicals (ROS) were investigated using ROS-Glo ${ }^{\mathrm{TM}} \mathrm{H}_{2} \mathrm{O}_{2}$ Assay (Promega). MM cells at a final concentration of $2.5 \times 10^{5}$ cells per milliliter of complete medium were plated in a 96-well-flat-bottom white microplate. After 2 and $4 \mathrm{hrs}$ incubation in the presence of $0 \mu \mathrm{M}, 25 \mu \mathrm{M}, 50 \mu \mathrm{M}$ and $100 \mu \mathrm{M} 3 \mathrm{BP}$, the luminescence which is proportional to the $\mathrm{H}_{2} \mathrm{O}_{2}$ concentration was measured using a Varioskan ${ }^{\mathrm{TM}}$ Flash Multimode Reader.

\section{Microscopic observation}

Materials were fixed in 4\% glutaraldehyde in phosphate-buffered saline (PBS, pH 7.4) for 8 hrs. Then, the samples were washed for $24 \mathrm{hrs}$ in $0.2 \mathrm{M}$ PBS $(\mathrm{pH}$ 7.4) and treated with $2 \%$ osmium tetroxide for $2 \mathrm{hrs}$. Then, 
Table 4: Oligonucleotides used for real-time PCR assays

\begin{tabular}{|c|c|}
\hline Primer & Sequence 5' - 3' \\
\hline GAPDH_For & GGCATGGCCTTCCGTGTCCC \\
\hline GAPDH_Rev & TGCCAGCCCCAGCGTCAAAG \\
\hline GSS_For & GCGGAGGAAAGGCGAACTA \\
\hline$G S S \_$Rev & AGAGCGTGAATGGGGCATAG \\
\hline GSR_For & TGGCACTTGCGTGAATGTTG \\
\hline GSR_Rev & CTCACATAGGCATCCCGCTT \\
\hline$G C L C \_$For & АСТTCATTTCCCAGTACCTTAACA \\
\hline GCLC_Rev & CCGGCTTAGAAGCCCTTGAA \\
\hline$G P X 1$ For & GCGGGGCAAGGTACTACTTA \\
\hline GPX1_Rev & TCTTGGCGTTCTCCTGATGC \\
\hline GSTP1_For & GCCCTACACCGTGGTCTATTT \\
\hline GSTP1_Rev & GGTCTCCGTCCTGGAACTTG \\
\hline$C N A G \_00483$ For & TCTGGTATGTGCAAGGCTGG \\
\hline CNAG_00483_Rev & CGTAAGAGTCCTTCTGGCCC \\
\hline$C N A G \_04647$ For & CCAACGAGAAGGTGGTGGAA \\
\hline CNAG_04647_Rev & TGACGAGCCAGTTCTCCAAC \\
\hline$C N A G \_02399$ For & TGACTTCAACTGGACCGAGC \\
\hline CNAG_02399_Rev & ACGGTGTACTTGTCGCCATT \\
\hline CNAG_06300_For & AGGCTATACCCGACCAGTGT \\
\hline CNAG_06300_Rev & ATGACTGCAGGTACGCACAA \\
\hline$C N A G \_02503$ For & TCGCCCAGTTTTGTACCCTC \\
\hline CNAG_02503_Rev & TGGTAAAGTTCCACTTGATGGC \\
\hline CNAG_01893_For & CGTCACTCACAAGTGCAAGC \\
\hline CNAG_01893_Rev & CTTTTCAAGATGAGCCGCCG \\
\hline
\end{tabular}

materials were rinsed for half an hour with distilled water, and finally dehydrated by successive immersion in a series of ethanol-water solutions $(55 \%, 70 \%, 80 \%, 90 \%, 96 \%$, $3 \times 100 \%$ ), for $15 \mathrm{~min}$ each. Subsequently, samples were transferred to cover slips and hexamethyldisilazane was applied and left to dry. In the next step, materials were mounted on a specimen stub and sputter-coated with spectrally pure carbon and silver in a sputter vacuum. The samples were examined in a scanning electron microscope (SEM) Tesla BS-300.

\section{Genes expression}

The expression level of selected genes within the genome of Cryptococcus neoformans (H99 reference strain) was examined based on the real-time polymerase chain reaction (real-time PCR). The overnight fungal cell cultures were incubated for $4 \mathrm{hrs}$ in minimal SD medium in the presence of different concentrations of $3 \mathrm{BP}(0 \mu \mathrm{M}$, $75 \mu \mathrm{M}$ and $150 \mu \mathrm{M})$. MM cells were incubated for 2 and 4 hrs in complete medium containing $0 \mu \mathrm{M}$ and $25 \mu \mathrm{M} 3 \mathrm{BP}$. The total RNA was isolated using the heat/freeze method [42]. The concentration of RNA was determined using a spectrophotometer (Nanophotometer Pearl, IMPLEN). Subsequently, isolated RNA was reverse-transcribed to cDNA using a high-capacity cDNA reverse transcription kit (Applied Biosystems). Gene expression was measured using a DyNAmo HS Green qPCR kit (Thermo Scientific Finnzymes) via a 7500 real-time PCR System (Applied Biosystems). The final volume of $20 \mu \mathrm{l}$ of each sample contained $0.5 \mu \mathrm{M}$ of each primer and $2 \mu \mathrm{l}$ of cDNA. The thermal cycling conditions were as follows: $95^{\circ} \mathrm{C}$ for 10 min, followed by 40 cycles at $95^{\circ} \mathrm{C}$ for $15 \mathrm{~s}, 58^{\circ} \mathrm{C}$ for 20 $\mathrm{s}$ and $72^{\circ} \mathrm{C}$ for $30 \mathrm{~s}$. The sequences of primers (designed based on the sequence of genes deposited in the GenBank database) are presented in Table 4. After completion of the 
reaction, the software (Applied Biosystems), based on the $\mathrm{Cq}$ value, calculated the relative quantity of the product for each gene. The CNAG_00483 (actin) and GAPDH in MM cells (housekeeping genes) were used for normalization. Results were obtained from three independent experiments in which the total RNA was isolated from the new culture.

\section{Statistical analysis}

Results are presented as the mean $\pm \mathrm{SD}$ from of at least three independent experiments. Statistical significance was assessed by one-way analysis of variance (ANOVA) using GraphPad Prism5, and with Tukey's multiple comparison test. The minimal level of significance was $P=0.05$.

\section{ACKNOWLEDGMENTS}

The authors are indebted to Joseph Heitman, Robin May, Hans de Cock, Urszula Nawrot and Tomasz Jagielski for kindly providing the selected strains of fungi and microalgae used in this study. We are also grateful to Dr Ryszard Adamski and Marek Chmielewski for technical help.

\section{CONFLICTS OF INTEREST}

The authors declare no conflicts of interest.

\section{FUNDING}

This work was supported by the Ministry of Science and Higher Education (Poland) via "Statutory Research 1016/S/IGM" and was also co-financed by the Polish National Science Center No. 2015/17/D/NZ2/01985 and No. 2015/19/N/NZ7/00956. Co-authors PLP and YHK are both supported in part by contributions from private donors. "The G. Yu Foundation supported in part YHK via KoDiscovery, LLC".

\section{REFERENCES}

1. Pedersen PL. 3-Bromopyruvate (3BP) a fast acting, promising, powerful, specific, and effective "small molecule" anti-cancer agent taken from the labside to bedside: introduction to a special issue $\mathrm{J}$ Bioenerg Biomembr. 2012;44:1-6.

2. Dyląg $\mathrm{M}$, Lis $\mathrm{P}$, Ko JH, Pedersen PL, Goffeau A, Ułaszewski S. Use of the composition of 3-bromopyruvate as a second application of a medicament for the treatment of fungal infections. Exclusive right number: patent no. 219802.

3. Ganapathy-Kanniappan S, Geschwind JF, Kunjithapatham R, Buijs M, Vossen JA, Tchernyshyov I, Cole RN, Syed LH, Rao PP, Ota S, Vali M. Glyceraldehyde-3-phosphate dehydrogenase (GAPDH) is pyruvylated during 3-bromopyruvate mediated cancer cell death. Anticancer Res. 2009; 29:4909-18.

4. Shoshan MC. 3-bromopyruvate: Targets and Outcomes. J Bioenerg Biomembr. 2012; 44:7-15.

5. Liu Z, Zhang YY, Zhang QW, Zhao SR, Wu CZ, Cheng $\mathrm{X}$, Jiang CC, Jiang ZW, Liu H. 3-bromopyruvate induces apoptosis in breast cancer cells by down regulating Mcl-1 through the PI3K/Akt signaling pathway. Anticancer Drugs. 2014; 25:447-55.

6. Warburg O. On the origin of cancer cells. Science. 1956; 123:309-14.

7. Casal M, Paiva S, Andrade RP, Gancedo C, Leão C. The lactate-proton symport of Saccharomyces cerevisiae is encoded by JEN1. J Bacteriol. 1999; 181:2620-3.

8. Lis P, Zarzycki M, Ko YH, Casal M, Pedersen PL, Goffeau A, Ułaszewski S. Transport and cytotoxicity of the anticancer drug 3-bromopyruvate in the yeast Saccharomyces cerevisiae. J Bioenerg Biomembr. 2012; 44:155-61.

9. Azevedo-Silva J, Queirós O, Ribeiro A, Baltazar F, Young KH, Peter L Pedersen PL, Preto A, Casal M. The cytotoxicity of 3-bromopyruvate in breast cancer cells depends on extracellular pH. Biochem. J. 2015; 467:247-58.

10. Ko YH, Smith BL, Wang Y, Pomper MG, Rini DA, Torbenson MS, Hullihen J, Pedersen PL. Advanced cancers: eradication in all cases using 3-bromopyruvate therapy to deplete ATP. Biochem Biophys Res Commun. 2004; 324:269-75.

11. El Sayed SM, El-Magd RM, Shishido Y, Yorita K, Chung SP, Tran DH, Sakai T, Watanabe H, Kagami S, Fukui K. D-Amino acid oxidase-induced oxidative stress, 3-bromopyruvate and citrate inhibit angiogenesis, exhibiting potent anticancer effects. J Bioenerg Biomembr. 2012; 44:513-23.

12. Pocsi I, Prade RA, Penninckx MJ, Glutathione, altruistic metabolite in fungi. Adv Microb Physiol. 2004; 49:1-76.

13. Rojas E, Valverde M, Kala SV, Kala G, Lieberman MW. Accumulation of DNA damage in the organs of mice deficient in gamma-glutamyltranspeptidase. Mutat. Res. 2000; 447:305-16.

14. Feng X, Zhang Y, Wang P, Liu Q, Wang X. Energy metabolism targeted drugs synergize with photodynamic therapy to potentiate breast cancer cell death. Photochem Photobiol Sci. 2014; 13:1793-803.

15. Dyląg M, Lis P, Niedźwiecka K, Ko YH, Pedersen PL, Goffeau A, Ułaszewski S. 3-Bromopyruvate: A novel antifungal agent against the human pathogen Cryptococcus neoformans. Biochem Biophys Res Commun. 2013; 434:322-7.

16. Reliene R, Schiestl RH. Glutathione depletion by buthionine sulfoximine induces DNA deletions in mice. Carcinogenesis. 2006; 27:240-4. 
17. Meister A. Glutathione metabolism and its selective modification. J Biol Chem. 1988; 263:17205-8.

18. Wolchok JD, Williams L, Pinto JT, Fleisher M, Krown SE, Hwu WJ, Livingston PO, Chang C, Chapman PB. Phase I trial of high dose paracetamol and carmustine in patients with metastatic melanoma. Melanoma Res. 2003; 13:189-96.

19. Hinson JA, Roberts DW, James LP. Mechanisms of acetaminophen-induced liver necrosis. Handb Exp Pharmacol. 2010; 196:369-405.

20. Rello S, Stockert J, Moreno V, Gamez A, Pacheco M, Juarranz A, Canete M, Villanueva A. Morphological criteria to distinguish cell death induced by apoptotic and necrotic treatments. Apoptosis. 2005; 10:201-8.

21. Majkowska-Skrobek G, Augustyniak D, Lis P, Bartkowiak A, Gonchar M, Ko YH, Pedersen PL, Goffeau A, Ułaszewski S. Killing multiple myeloma cells with the small molecule 3-bromopyruvate: implications for therapy. Anticancer Drugs. 2014; 25:673-82.

22. Nagata S. Apoptotic DNA fragmentation. Exp Cell Res. $2000 ; 256: 12-8$

23. Lawen A. Apoptosis - an introduction. Bioessays. 2003; 25:888-96.

24. Ko YH, Verhoeven HA, Lee MJ, Corbin DJ, Vogl TJ, Pedersen PL. A translational study "case report" on the small molecule "energy blocker" 3-bromopyruvate (3BP) as a potent anticancer agent: from bench side to bedside. $\mathrm{J}$ Bioenerg Biomembr. 2012; 44:163-70.

25. Ko YH, Smith BL, Wang Y, Pomper MG, Rini DA, Torbenson MS, Hullihen J, Pedersen PL. Advanced cancers: eradication in all cases using 3-bromopyruvate therapy to deplete ATP. Biochem Biophys Res Commun. 2004; 324:269-75

26. Lis P, Jurkiewicz P, Cal-Bąkowska M, Ko YH, Pedersen PL, Goffeau A, Ułaszewski S. Screening the yeast genome for energetic metabolism pathways involved in a phenotypic response to the anti-cancer agent 3-bromopyruvate. Oncotarget. 2016; 7:10153-73. doi: 10.18632/ oncotarget.7174.

27. Kim JS, Ahn KJ, Kim JA, Kim HM, Lee JD, Lee JM, Kim SJ, Park JH. Role of reactive oxygen species-mediated mitochondrial dysregulation in 3-bromopyruvate induced cell death in hepatoma cells: ROS-mediated cell death by 3-BrPA. J Bioenerg Biomembr. 2008; 40: 607-18.

28. Calviño E, Estañ MC, Sánchez-Martín C, Brea R, de Blas E, BoyanoAdánez Mdel C, Rial E, Aller P. Regulation of death induction and chemosensitizing action of 3-bromopyruvate in myeloid leukemia cells: energy depletion, oxidative stress, and protein kinase activity modulation. J Pharmacol Exp Ther. 2014; 348:324-35.
29. Zhang Q, Zhang Y, Zhang P, Chao Z, Xia F, Jiang C, Zhang X, Jiang Z, LiuH. Hexokinase II inhibitor, 3-BrPA induced autophagy by stimulating ROS formation in human breast cancer cells. Genes Cancer. 2014; 5:100-12. doi: 10.18632/ genesandcancer.9.

30. Devasagayam TP, Tilak JC, Boloor KK, Sane KS, Ghaskadbi SS, Lele RD. Free radicals and antioxidants in human health: current status and future prospects. J Assoc Physicians India. 2004; 52:794-804.

31. Sadowska-Bartosz I, Bartosz G. The effect of 3-bromopyruvic acid on human erythrocyte antioxidant defense system. Cell Biol Int. 2013; 37: 1285-90.

32. Hellou J, Ross NW, Moon TW. Glutathione, glutathione S-transferase, and glutathione conjugates, complementary markers of oxidative stress in aquatic biota. Environ Sci Pollut Res. 2012; 19:2007-23.

33. Li ZS, Szczypka M, Lu YP, Thiele DJ, Rea PA. The yeast cadmium factor protein (YCF1) is a vacuolar glutathione S-conjugate pump. J Biol Chem. 1996; 271:6509-17.

34. Atkinson HJ, Babbitt PC. Glutathione transferases are structural and functional outliers in the thioredoxin fold. Biochemistry. 2009; 48:11108-16.

35. Eaton DL, Bammler TK. Concise review of the glutathione S-transferases and their significance to toxicology. Toxicol Sci. 1999; 49:156-64.

36. Manna SK, Kuo MT, Aggarwal BB. Overexpression of $\gamma$-glutamylcysteine synthetase suppresses tumor necrosis factor-induced apoptosis and activation of nuclear transcription factor-kappa B and activator protein-1. Oncogene. 1999; 18:4371-82.

37. Sadowska-Bartosz I, Soszyński M, Ułaszewski S, Ko Y, Bartosz G. Transport of 3-bromopyruvate across the human erythrocyte membrane. Cell \& Mol Biol Lett. 2014; 19: 201-14.

38. Amberg DC, Burke DJ, Strathern JN. Methods in Yeast Genetics. A Cold Spring Harbor Laboratory Course Manual. Cold Spring Harbor Laboratory Press, 2005, New York, USA.

39. Isenberg HD. Clinical Microbiology Procedures Handbook, 1 ed., Washington, American Society for Microbiology, 1992.

40. Gonzalez B, François J, Renaud M. A rapid and reliable method for metabolite extraction in yeast using boiling buffered ethanol. Yeast. 1997; 13:1347-55.

41. Ellman GL. Tissue sulfhydryl groups. Arch Biochem Biophys. 1959; 82:70-7.

42. Schmitt ME, Brown TA, Trumpower BL. A rapid and simple method for preparation of RNA from Saccharomyces cerevisiae. Nucleic Acids Res. 1990; 18:3091-2. 